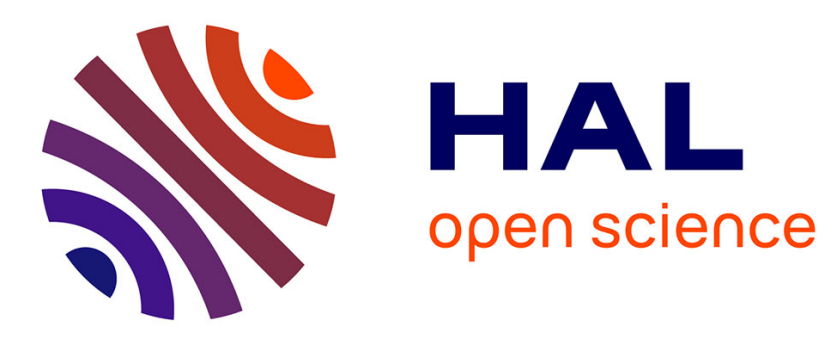

\title{
Managing end-of-life vehicle networks: a longitudinal case of the UK
}

Joe Miemczyk, Andrew Graves

\section{To cite this version:}

Joe Miemczyk, Andrew Graves. Managing end-of-life vehicle networks: a longitudinal case of the UK. International Journal of Automotive Technology and Management, 2007, 7 (4), pp.356-370. 10.1504/IJATM.2007.017066 . hal-00796844

\section{HAL Id: hal-00796844 \\ https://hal-audencia.archives-ouvertes.fr/hal-00796844}

Submitted on 23 Feb 2015

HAL is a multi-disciplinary open access archive for the deposit and dissemination of scientific research documents, whether they are published or not. The documents may come from teaching and research institutions in France or abroad, or from public or private research centers.
L'archive ouverte pluridisciplinaire HAL, est destinée au dépôt et à la diffusion de documents scientifiques de niveau recherche, publiés ou non, émanant des établissements d'enseignement et de recherche français ou étrangers, des laboratoires publics ou privés. 


\title{
Managing end-of-life vehicle networks: a longitudinal case of the UK
}

\author{
Joe Miemczyk ${ }^{1}$ \\ Audencia, Ecole De Management, Nantes \\ Nantes, France \\ E-mail:jmiemczyk@audencia.com \\ Andrew Graves \\ Innovative Manufacturing Research Centre, University of Bath School of Management, \\ Bath BA2 7AY, UK \\ Tel: +44 1225386641 Fax +44 1225386135 \\ Email: mnsapg@management.bath.ac.uk
}

\begin{abstract}
This research outlines the development of end of life vehicle network management in the UK from the early 1990s to mid-2006. The paper critically appraises the developments over a decade and a half from the development of a voluntary scheme to a legislated regime for recovering end of life vehicles with the goal of reducing landfill waste. The research assesses the management implications (economic implications and industrial responses) of a voluntary versus legislated approach, with regard to legitimacy and competitiveness drivers within vehicle manufacturers and service providers (vehicle dismantlers).
\end{abstract}

Keywords: End of life vehicles, strategy, case study, United Kingdom

Bibliographical Notes: Joe Miemczyk is Assistant Professor in Operations and Supply Chain Management at Audencia, Nantes, France. Previously, he has worked on the 3DayCar programme and was most recently theme leader on the European ILIPT project. Joe has published widely on in the area of automotive logistics and has presented at a number of conferences in operations management, logistics and environmental management.

Andrew Graves is Professor of Technology Management at The University of Bath and directs research into Lean Manufacturing and Agile Production within the IMRC (Innovative Manufacturing Research Centre). He is a mechanical engineer and political scientist and began his industrial career as a trainee manager with the Rootes Group in 1966. At the Science Policy Research Unit at the University of Sussex he undertook research with MIT's IMPV (International Motor Vehicle Programme) on R\&D and technology issues and subsequently became European Programme Director to the programme.

\footnotetext{
${ }^{1}$ Corresponding author
} 
This research outlines the development of end of life vehicle network management in the UK from the early 1990s to mid-2006. The paper critically appraises the developments over a decade and a half from the development of a voluntary scheme to a legislated regime for recovering end of life vehicles with the goal of reducing landfill waste. The research assesses the management implications (economic implications and industrial responses) of a voluntary versus legislated approach, with regard to legitimacy and competitiveness drivers within vehicle manufacturers and service providers (vehicle dismantlers).

At the present time the UK industry is in the throes of conforming to the European End of Life Vehicle Directive, one of a raft of producer responsibility directives designed to ensure that the environmental impacts of products are minimised by making their manufacturers responsible for at least some of the costs of recovery, treatment and recycling. Vehicle manufacturers have established contracts with recyclers that conform to the directives stringent requirements on environmental protection, and at the same time government at various levels has put in place enforcement regimes aimed at ensuring the directives can be met. This has meant serious investments in capital and other resources by all the parties involved, as well as a general re-structuring of the vehicle recycling industry overall.

Yet there is a significant history to end of life vehicle management in the UK. Firms in the car producing and recycling (dismantling, shredding) industries are not coming to this issue without an extensive amount of experience, quite the opposite. Furthermore, firms can be a hostage to their own history, and institutional theory tells us that practices and routines of firms can commonly be seen as built up through time as habitual actions more than rationalised decisions based on fact and logic. To understand these interactions it is important to look at strategic changes over time. While, actions such as end of life vehicle management are often viewed at a network level, it is the collective behaviour of individual organisations that determine whether legislated targets set at EU level can be met. Hence this study takes the perspective of individual firm strategy within a network context. To aid the understanding of how firm strategy has developed, the study also takes a longitudinal approach in an attempt to elucidate how firms can affect and be affected by changes in the institutional environment.

Section 1 has given a general introduction to the problem area. The paper continues with section 2 covering some of the key literature in the field of end of life vehicle management, as well as some of the recent management thinking that informs the discussion elements of the paper such as network management, capabilities and legitimacy (through formal regulatory pressures). An outline of the methodological approach is given in section 3 . The principal findings are given in section 4 which is divided into 5 sections covering 4.1) the original voluntary approach 4.2) legislated actions, 4.3) structural network changes 4.4) the development of network relationships 4.5) capability development and 4.6) attitudes to changes in the network and process. The paper closes with conclusions and indications for further research.

\section{Background literature}

Much of the management literature focussed on the end of life vehicle issue originates from the late 1990s when the ELV Directive (CEC 2000) was first likely to become enshrined in EU law. A number of authors examined the management aspects of reforming ELV organisation (Den Hond et al 1993, Den Hond 1998). In particular these authors have examined how capabilities for vehicles recycling have been developed by sharing knowledge between vehicle producers, dismantlers and other experts in the field, often in collaborative arrangements. While this research has focussed on the strategic implications, for example adopting a resource based perspective, the dynamic nature of capabilities and the changing legislative landscape call for longitudinal viewpoints.

Some authors examined the issues from an engineering perspective in an attempt to provide an micro-economic analysis of different recovery strategies. This is useful in terms of developing models that could be applied to different contexts accounting for labour cost and technology differentials (Johnson and Wang 2002). Some researchers have used less commonly applied theoretical frameworks such as political ecology in order to provide further understanding of the changes occurring in the industry (Orsato et al 2002). Importantly, the institutional fields having considerable influence on firm strategies have also been considered through various econo-political viewpoints, for example discussing the role of incentives for innovations in the end of life vehicle field especially were these may be mis-aligned or give undesirable results (Mazzanti and Zoboli 2005). Yet literature does not consider the business strategy dynamics of evolving network structures and processes, particularly at the network level. This paper examines the development over time of both the structural elements of vehicle recovery from a network and process perspective, as well as the capability development implications of network members, and 
potentially the network as a whole. The management literature is replete with research that has covered various aspects of these important domains and the following part of this literature review provides an extremely brief outline of current thinking.

With regard to the network perspective, management researchers have drawn on a wide range of disciplines to enhance understanding. The network view can be stated as a conceptual or analytical tool which provides a complete view of the social environment encompassing relationships, a structure for a set of persons or structural description of a network based on the characteristics of relationships (Shulman 1976). General types of networks include the following (Lamming et al. 2000): social networks such as industrial districts; Bureaucratic networks such as trade associations and consortia with exchange or associational contractual agreements and joint and/or capital ventures with equity and property rights. In particular, sociological approaches to 'network' research has had a particularly influential role. Early researchers have often used concepts such as network centrality structurally this means the number of direct ties to others in the network and/or independent access and/or control over other actors - to explain how organisations (or individuals) affect or are affected by networks, for example in the ability to acquire knowledge. From the perspective of relationships and firm performance, it is proposed that competitive advantage can be gained by strategically managing the network (Harland 1996). However the Scandinavian school of supply, in taking a resource dependency perspective, state that networks cannot be managed, only coped with (Hakansson and Snehota 1995). Recent research into networks has revealed that firms may be in an enhanced competitive position because their network structures allow them to exploit their internal capabilities more effectively, whereby the innovativeness of network partners indirectly supports the focal firm's performance (Zaheer and Bell 2005). McEvily and Markus (2005) also find that the acquisition of capabilities is facilitated through network embedded ties and alliances and argue that while both trust and information sharing are important, joint problem solving is also key to transferring knowledge. This discussion of the role of networks and the network perspective has quickly turned to how networks can be a source of advantage through capability acquisition or development. Hence it is clear that a brief discussion of recent thinking on capabilities is also required.

Recent definitions of capability include "a high level routine (or collection of routines) that, together with its implementing input flows, confers upon an organization's management a set of decision options for producing significant outputs of a particular type" (Winter 2003: 991) or "a capacity to integrate, combine, and deploy tangible and intangible resources through distinctive organisational processes in order to achieve desirable objectives" (Lavie 2006a: 153). The discussion of capabilities provides an explanation for how firms achieve competitive advantage through the deployment of idiosyncratic resources that competitors do not possess and are not able to imitate. The role of collaboration in providing resources and hence benefits to firms has been a recent development in the capability perspective (For example Das and Teng 2000; Dyer and Singh 1998; Lavie 2006b). Although often applied to strategic alliances this previous work is useful in explaining how the alignment of capabilities through similarity and utilisation, and importantly, has identified that the expectations for certain capabilities does not always lead to the expected 'positive' outcomes in terms of performance such as cost reduction, efficiency and so forth.

\section{Method.}

A detailed case analysis of the attempt development of vehicle recycling networks in the UK forms the empirical core of the paper. Case studies are particularly useful when exploring new areas of research (Voss et al., 2002; Stuart et al., 2002, Eisenhardt, 1989) and equally, the rich qualitative and quantitative data sets generated (Yin, 1994) are particularly important because the measurement of intangible phenomena e.g. roles and relationships (Denzin and Lincoln, 2005) was a central concern. Studies of organizations or sectors remain popular in management research because they offer the opportunity for deep, longitudinal analysis, exploring the impact of organizational change and often involve the development of conceptual frameworks or interpretative schemes (Mueller et al., 2003).

Primary data was collected using semi-structured interview questions, each interview lasted between 2 and 3 hours, investigating the sub-elements defined by the conceptual model (i.e. operational, processual and contextual factors) and the respondent-driven Critical Incident Technique (CIT) (Flanagan, 1954; Bitner et al., 1990; Edvardsson, 1992). The former aims at a global case description and understanding of the behaviour of firms over time, whereas the latter is used to map micro-level incidents as individual respondents experience them. For this purpose we defined an event to be 'a retrospective organisation of a set of inter-related incidents into a comprehensive narrative' and for an event to be classified as 'critical' meant that it 'was perceived to have had a 
positive or negative outcome for a person or the organisation'. A chronology of activities by the companies leading up to and after the implementation of the ELV Directive in the UK was created as a guide to familiarise the investigators with contemporary events in the research context.

The research findings are based on primary interviews with OEMs, dismantlers and policymakers (including Nissan, Honda, PSA, Ford, Volvo, GM Europe, Jaguar, SMMT and the DTI ). The method utilises a case approach that also encompasses site visits and reviews of company documentation and other secondary data. In addition, mapping workshops with dismantlers and vehicle manufacturers were carried out to gain a structural view of the changing nature of the relationships.

\section{$4 \quad$ Managing end of life vehicle networks (2000-2006)}

Between 2000 and 2006 there have been a number of critical events and developments which have shaped today's recovery networks. These events include the development of industry groups, a voluntary agreement, the dissolution of the industry group, the staged and delayed implementation of EU legislation and many meetings between industry bodies, firms and legislators in the UK and EU.

\subsection{The original voluntary approach}

The main action in the UK related to the voluntary approach is the ACORD agreement set up by the Society of Moter Manufactures and Traders on behalf of UK vehicle manufacturers. This agreement put in place measures of vehicle recycling in order to track the level of vehicle recycling in the UK. The main purpose of this agreement was to provide a possible alternative to legislation that was being mooted at European Union levels. If the ACORD agreement could demonstrate to legislators that regulation was not necessary to achieve high levels of recycling (eg 90\%), then there would be the possibility that industry could avoid additional regulatory burdens on top of those that are already in place, such as the packaging regulations, IPPC, passive safety requirements and various other laws which have increased the society pressures on the automotive sector (in additional to those that already affect the product in terms of safety, fuel efficiency and exhaust emission). The following table show what the ACORD agreement achieved between 1997-2001 in terms of vehicles recycling. Interestingly, due to uncertainty about the ELV directive in terms of recycling targets, certainty over the implementation of the new European law, the efforts to measure recycling levels in the UK ended in 2001.

\begin{tabular}{lllll}
\hline & 1997 & 1998 & 1999 & 2000 \\
\hline Number of ELVs & 1900000 & 1800000 & 1800000 & 2017137 \\
\hline $\begin{array}{l}\text { Recovery } \\
\text { percentage }\end{array}$ & $76 \%$ & $74 \%$ & $77 \%$ & $80 \%$ \\
Recy & & & &
\end{tabular}

Table 3: Recycling levels under the ACORD agreement (Source: SMMT)

In addition to the ACORD agreement in the UK, the SMMT also facilitated the set up of the CARE group. The CARE group is a membership based organisation established to provide a forum for knowledge sharing on the subject of ELV as well as establishing standards for vehicle recovery. The group holds regular meeting at dismantler sites to discuss current developments in the field and transfer this knowledge across other members of the group, representing both vehicle dismantlers and vehicle manufactures and other associated members. Through the membership funds and coordination activities the group is able to start research projects in certain areas to assess the feasibility of specific technologies or processes that could increase the level of vehicle recycling. For example the group recently completed a feasibility study of recycling plastic bumpers into reusable plastic granules, focussing on how to obtain sufficient volumes from service repair workshops and potentially from dismantlers end of life vehicles.

The CARE group itself ran into some difficulties during the implementation of the ELV regulations in the UK. Due to the extreme focus on the regulation and the efforts required, efforts in CARE stalled in terms of developing projects and so on. In fact there was a stage in 2002 that many thought that CARE would have to be disbanded as the regulation created a lack of consensus over the future of ELV management in the UK. Since the resolution of the ELV regulation in the UK, the CARE group has a re-asserted itself as a useful mechanism for sharing knowledge in the area, specifically focussing on how to achieve the more challenging aspects of the recycling targets such as the so called 'last 9\%' and reducing costs of compliance for all parties. Thus fears of not continuing 
this apparently important vehicle for knowledge sharing have not been realised to date, and the group continues to hold meetings at dismantler sites and initiate research or feasibility studies.

\subsection{Legislated action}

The UK vehicle producers quickly organised themselves under the umbrella of the SMMT to ensure that a coordinated effort was made to ensure that the transferral of the ELV directive into UK regulation as made with business interests in mind. In fact it was always the publicly stated intention of the UK government to implement the EU ELV directive with a light touch. As the then secretary of state reported "We have consistently made clear our intention to implement the end of life vehicles directive with a light regulatory touch and without disrupting the existing legitimate dismantling, shedding and recycling market".

In developing the UK response to the ELV directive the DTI and Defra coordinated a number of consultations on the implication of the regulation on UK businesses.

Among other EU states the UK was late implementing the ELV directive. A number of bodies threatened to bring legal action against HM Government. This also created considerable uncertainty for the companies actually implicated in the regulation. On the one hand this gave ample time for the industry groups to provide responses to the various consultations, yet on the other hand left less time for companies to actually meet the various implementation deadlines set at EU level.

\subsection{Network structure}

One of the most striking differences between the structure of the recovery networks in 2000 compared with 2006 is the reduction in treatment sites. With the new regulatory requirements on recovery standards, many sites are not able to justify the necessary investments in order to become authorised treatment facilities (ATFs) in the eyes of legislators, notably the Environment Agency (see Table 1). While the current number of sites is roughly half that of six years before, it can be stated that this overall level will continue to increase as dismantlers continue to invest to upgrade their facilities and the Environment Agency, which is severely resource constrained, is able to provide authorisation to existing sites that have made the necessary investments.

\begin{tabular}{lll}
\hline Dismantlers 2000 & $\begin{array}{l}\text { Authorised } \\
\mathbf{2 0 0 6}\end{array}$ & dismantlers \\
\hline $3375(2426)$ & 1189 & \\
\hline
\end{tabular}

Table 2: Structure of the recovery networks $(2000-2006)^{2}$

There are a number of implications of this reduction in the overall number of sites available for recovering ELVs. These include, among others, limitations in market choice and oligopolistic practice. In particular the reduction in market choice could theoretically decrease the competition between dismantlers, and therefore notionally raise prices for the 'recovery' service, especially as the geographical spread of dismantlers is partly influenced by the regulation, in that vehicle producers must show evidence that their network meets certain geographical constraints. This could mean that in certain areas where there are few dismantlers which are authorised, the supply of service is restricted, increasing prices for depollution. In reality, the vehicle manufacturers contract through one or two recovery 'brokers' who effectively manage the network, and who can at least have visibility of the 'market' prices for recovery services, and work to ensure limited supply is minimised as much as possible.

The network diagram summarises the linkages between the main players in the ELV recovery network today (figure 1). The main difference from the original voluntary scheme that was in place with ACORD is there are now a number of intermediaries who act as brokers between the OEMs and the actual network of dismantlers across the UK. In order to avoid the situation where OEMs have to manage contracts with multiple dismantlers (in order to ensure that there is a nominated site sufficiently close to last users) the broker manages these relationships on behalf of the OEM. This type of development is common in the automotive sector (where $1^{\text {st }}$ tier suppliers take on the responsibility of managing many traditional suppliers).

\footnotetext{
${ }^{2}$ Figures based on MVDA, Environment Agency and World parts - in brackets) for 2000 and Environment agency for 2006
} 


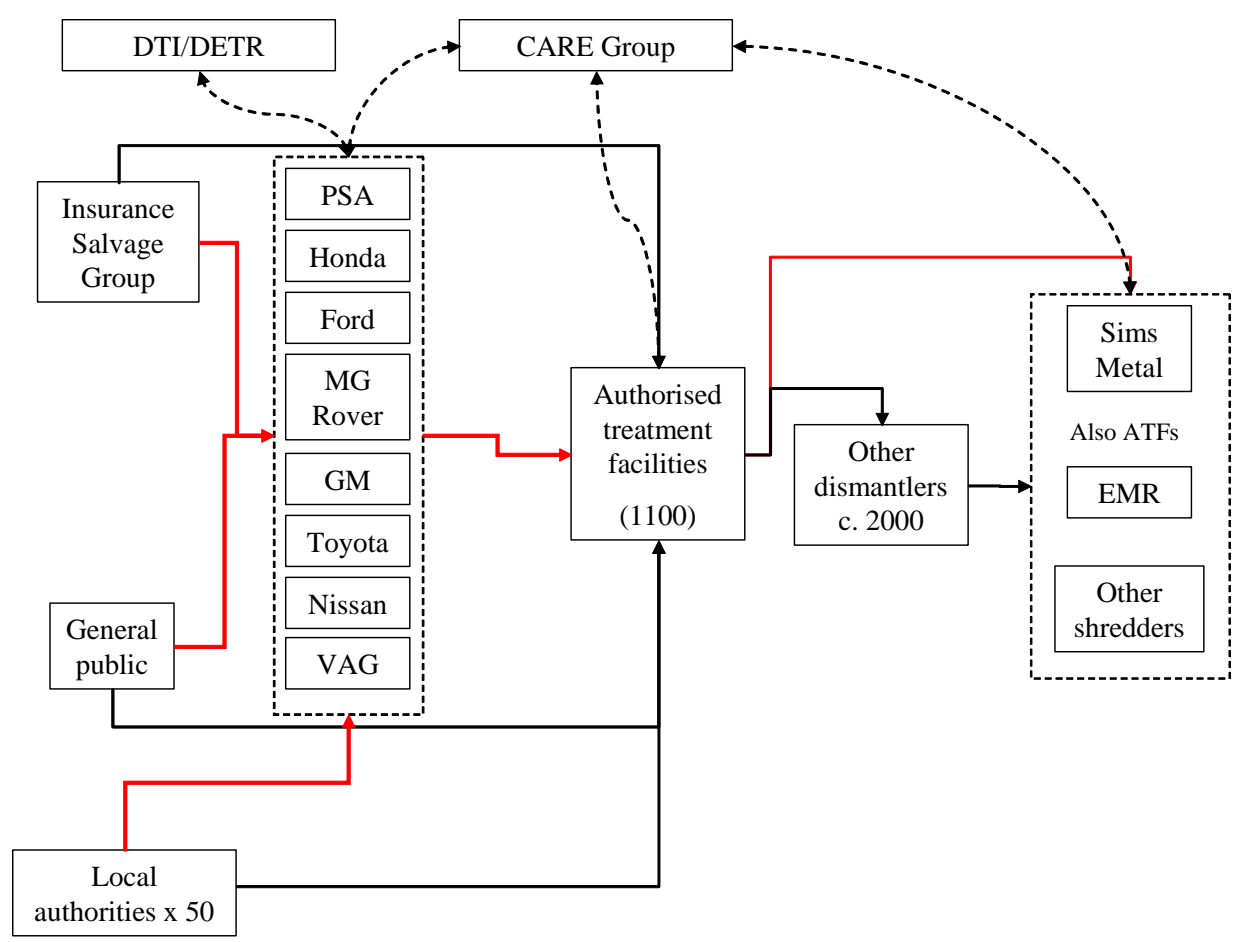

Figure 1: Managing end of life networks: changing business relationships (scope of study)

One of the most significant impacts of the new legislative regime is that the business relationships have changed.

\begin{tabular}{ll}
\hline 2000 (Voluntary approach) & 2006 (Legislated approach) \\
\hline CARE group membership & Contracts with Autogreen \\
ACORD Agreement & Contracts with Cartakeback \\
Selected dismantlers for trials & Contracts for factory scrap vehicles \\
Contracts for factory scrap vehicles & $\begin{array}{l}\text { Remanufacturing (Engines \& } \\
\text { transmissions) }\end{array}$ \\
Remanufacturing (Engines \& transmissions) &
\end{tabular}

Table 3: Contractual relationship changes (2000 - 2006)

\section{$4.4 \quad$ Network relationships}

As can be seen from the table (Table 4) below, and figure of the relationship maps, two key end of life vehicle brokers have emerged to provide a compliance solution to the main vehicle producers that sell vehicles in the UK. These two recovery 'brokers' act as a bridge between the vehicle manufacturers and the dismantling network, providing evidence on behalf of the vehicle producers that they have a compliant network in place (for example to the Department of Trade and Industry). Both Autogreen and Cartakeback will ensure that end users of any particular marquee of vehicle will be able to take their end of life vehicle to a 'close by' dismantler at no cost to the end user. The recovery 'broker' will also manage the flow of data on recycling levels across the complete network of dismantlers and report this back to vehicle manufacturers to provide the basis for how the network is contributing to the overall UK recovery targets.

\begin{tabular}{ll}
\hline Autogreen & Cartakeback \\
\hline BMW, Daihatsu, Cadillac, Chevrolet, Chrysler, Daewoo, & Alfa Romeo, Alpine, Aston Martin, Audi, Austin, \\
Dodge, Ferrari, Honda, Isuzu, Jeep, Maserati, Maybach, Bentley, Bugatti, Citroën, Dacia, DAF, Datsun, Dodge, \\
Mercedes-Benz, MINI, Mitsubishi Canter, Porsche, & Fiat, Ford, Hillman, Humber, Hyundai, Iveco, Jaguar, \\
Saab, SMART, Subaru, Suzuki, Toyota/Lexus and Lamborghini, Lancia, Land Rover, LDV, Leyland, & $\begin{array}{l}\text { Land, } \\
\text { Vauxhall }\end{array}$ \\
& Leyland DAF, Lotus, Matra, Mazda, MG, MG X- \\
& Power, Mitsubishi, Morris, Nissan, Perodua, Peugeot, \\
& Proton, Renault, Renault Trucks, Riley, Rover, SEAT, \\
& Simca, Singer, Skoda, Sunbeam, Talbot, Tata, Tatra, \\
& Triumph, Volkswagen, Volkswagen Commercial, \\
\hline
\end{tabular}




\section{Table 4: Current contracts with the main UK recovery service providers (various public sources)}

To an extent OEMs have little strategic interest in integrating product recovery capabilities unless there is a direct effect on their competitive strategy (gaining new markets for example with remanufactured products), and thus contracting to meet regulated norms is the preferred approach. OEMs of this study are intent on meeting legitimacy goals through a least cost approach and are thereby focussed on accessing and developing capabilities that support that aim. Hence, OEMs require collaborative relationships to ensure that service providers can help them meet that aim (through sharing of information and knowledge about product designs and distribution networks), and it is the combination of capabilities that allows the meeting of these goals.

In particular the case of GME and Autogreen showed evidence that the relationship could be developed further to include new area of collaboration, for example in developing a 'green' line of used parts, branded under GM. These were just ideas, but show the potential for existing relationships to be developed further in support of product stewardship. Thus, although a standard set of contracts have been issued between dismantlers and vehicle manufacturers, there is certainly scope to expand the depth of these relationships in order to perhaps capitalise on further synergies (technologies, skills, knowledge) to provide value not just in terms of compliance but also differential costs compared to competing brands and also potentially new revenue streams for both dismantlers and vehicle producers. Hence, the networks could be viewed as providing a basis for building new market opportunities, that could theoretically at least support the targets for recovery (through re-use of parts and components).

\subsection{Capabilities}

One interesting debate occurring between network members in the argument over the capability for recovering through shredding versus capability for recovery through dismantling. The research highlights an interesting example for how different capabilities are potentially in conflict, specifically in the comparison of the shredder or dismantler approach. A recent market experiment was set up between members of the CARE group and a plastic recycler to assess whether significant levels of plastic from car bumpers could be recovered at a low cost. One of the significant results from this study was that while high levels of plastic material could be recycled into re-usable plastic granulate the cost advantage of doing so was nearly equalised by the reduction in revenues from the hulks sold to shredders (which were less heavy).

Specific skills for recovery are still required by many members of the network in the UK. In particular handling items such as airbags and air-conditioning units is complex and fraught with safety and compliance difficulties. In order to cope with this deficiencies in the skills of network companies, the 'knowledge-sharing' groups such as CARE activity provide access to training and current knowledge on this types of issues. Yet at the same time all network members have equal access to these skill acquisition routines and as such form a generic level of capability development applied to the whole sector, separated from areas of commercial sensitivity or competitive advantage. Thus the network structure in place tend to allow for the development of 'industry' or 'sector'-level capability development, providing something akin to a level playing field for compliance. Clearly it is not in the interests of government agencies to allow differentiation based on compliance (non, low levels or high levels of compliance), and certainly firms are not incentivised to go beyond the level of compliance, within the previous or current frameworks of vehicle recovery.

Building on the substantial literature on social capital (Nahapiet and Ghoshal 1998), the ability to network to find expertise by OEMs appears to be a function of their network ties (within trade associations, industry working groups as well as their collaborative relationships with service providers) and allows the identification of suitable partners in the product recovery supply chain. This research also finds that the service providers ability to provide revenue to reduce compliance costs is key to the economics of product recovery (whether through re-use, remanufacturing or recycling) and is built up over time, again through supply chain network ties, but in this case of the service providers. These capabilities tend to be pre-existing within the firms and are accessed by the OEMs planning to establish a product recovery process. The research highlights a couple of instances where capabilities (not identified in other research) are developed through the collaborative relationships and these specifically relate to re-establishing the customer link and building legitimacy. The issue of legitimacy, and perhaps the effect on reputation is difficult to link to competitive advantage. Whether end users are more likely to used dismantlers with higher levels of 'legitimacy' remains to be seen, but seems an unlikely differentiator. 
The activities of the OEMs to access and develop new capabilities in response to market (or business environment) changes, could be viewed in terms of dynamic capability (Winter 2003), a meta-capability that has been defined as "processes to integrate, reconfigure, gain and release resources-to match and even create market change" (Eisenhardt and Martin 2000: 1107). This type of capability, however, is contingent on firms being able to exercise some degrees of freedom in their response. As shown in the case companies of this research, firms can be constrained in their response to varying degrees. Although collaborative relationships (and their role in providing social capital for example) may form a facilitator in integrating, reconfiguring and gaining resources, and thus capabilities (Blyler and Coff 2003), the constraints of pre-determined pathways and mandated procedures for product recovery limit the usefulness of this explanation. Given that collaborative relationships do, on occasion, lead to the access to and development of capabilities for product recovery, for these capabilities to be of competitive value they must improve performance in some way. The question then arises who actually gains from this improvement. Is it the dismantlers, in terms of lower dismantling costs or is manufacturer who will need to pay less for vehicles with a negative value.

This narrow focus on firm advantage has been challenged on a number of quarters. As Mathews (2003) argues benefits also can be at an industry level (drawing on the evolutionary view of the firm), so that shared capability development, or least the development of capabilities that can be of equal access to other industry players is not necessarily in opposition to competitive positioning at an industry level. Thus taking this 'extended resource-based view' implies that capabilities that are not idiosyncratic and can easily be transferred to other firms in an industry could actually benefit the competitiveness of an industry overall. Managers that view product recovery as 'noncompetitive' may support this concept of industry level competitiveness at least at a regional level (perhaps where regions compete against regions - Europe and the Far East as examples).

\subsection{Attitudes towards changes in ELV recovery}

For the main part, this discussion has centred round a structural view of the changes in relationships between actors across industries. An examination of attitudes of industry players provides a deeper understanding of the strategic implication of the changes in the way ELVs are handled in the UK. Overall attitudes towards the changes to network structure over the period indicate a major re-organisation of the competitive environment for ELVs in the UK. "It's a shrinking market". The OEMs primary objective with regard to ELV legislation is to be legal, e.g., "the number one objective is to be legal"(OEM manager), which reinforces the view that this cannot be viewed as a strategic priority but an operational necessity. Alongside this objective is the need to reduce the costs and liabilities of the regulated norms, e.g "..everybody's looked at it and it is incredibly difficult to make this work financially, by working on your own," again highlighting the need to collaborate with "competitors to gain economies of scale. Furthermore ELV is not seen a competitive priority in general, "materials recycling is one area we don't perceive ourselves as being the best in the industry". OEM liability is restricted to only providing a free take back service to end users, when a vehicle is of negative value "when it comes to the recycling targets unless the legislation changes a great deal I don't think manufacturers see too many individual risks". Thus the implementation of the ELV Directive has moved from a phase of risk minimisation (due to financial accruals), to a realisation that the strategic threat is rather smaller than expected originally.

\section{Conclusions}

OEMs still view the ELV issue as a low competitive priority compared to other environmental concerns. Yet at the same time there are high liability risks (due to financial accruals).In the UK, the new network organisation implies a market approach, yet within an atmosphere of limited competition. To an extent the risks of opportunism on the part of contractors are overcome with visibility (legislated and contracted). The case provides lessons for voluntary versus legislated approaches, and the strengths and weaknesses of both. The main challenge on the corporate agenda is balancing competitiveness and legitimacy concerns.

Looking at the development of the ELV issues in the UK over the last decade and a half highlights some interesting insights. The first is that a proactive voluntary approach will not necessarily stave off a legislated action. Although management strategists claim such benefits of proactive environmental strategy (Porter 1991; Hart 1995), this case demonstrates this is not always the case and should not be relied upon. The second main point is that while the voluntary approach has not survived in terms of structure and process, the network links that have been developed remain and have been very important in the response made by industry. In particular, the ability of the industries to act together to influence the exact way the legislation was interpreted is believed by the 
authors to be one reason why the UK may be seen as having an 'efficient' mechanism for complying to the ELV Directive.

\subsection{Managerial implications}

As this study has primarily taken a strategic capabilities perspective the main managerial implications follow from this. The first point to make is that ELV continues not to be a strategic imperative for vehicle manufacturers (despite a brief period when finance directors at board level were busy calculating the impact of financial accruals on their fragile share valuations). Many other issues compete more successfully to win board level discussion time. However, that is not to say that there could be competitively valuable opportunities. As some vehicle manufacturers have indicated, there may be opportunities outside of the legislative constraints. Some firms are spending time to develop their aftermarket strategies to expand there markets for 'branded' reconditioned parts and perhaps get closer to vehicle last users, as potential new customers.

A further managerial implication is the peculiarity of the UK ELV approach. Under the present organisation, many vehicle manufacturers have contracts with a limited number of dismantlers to ensure they have take back network in place, often coordinated through a single broker this is far from ideal for any 'buyer' of service, albeit mandated ones. To ensure that opportunism on the part of dismantlers is minimised, contracts are more akin to supply partnerships, common in the automotive industry. However, without significant investment in the relationship on both sides (information sharing, joint decision making, etc) there are still risks of opportunism. Thus vehicle manufacturer managers must still be vigilant to ensure that the true costs of ELV treatment and recovery are passed on, and still more wary that the true costs associated with their particular brand and models are visible.

The struggle between a dismantling process approach against a shredder based approach is a significant one. It is still to be shown which will be the most effective at achieving the recycling targets at the lowest cost. Shredders claim that the last $9 \%$ (made up of plastics etc) is most likely to be recovered with an approach based on post shredder technologies due to the economies of scale which are possible on a material separation level. While prices for complete components sold on the second hand market would give a better return by weight (despite the costs of dismantling), the ability to meet recycling targets is highly dependent on the consumer demand for parts (both in terms of volume and price sensitivity). More studies in this area are required to find the optimal process.

\subsection{Political implications}

One of the main implication for policy-makers is to clearly legislate so that firms are incentivised to improve their environmental performance, under market forces. Under the current arrangements, car manufacturers are hardly incentivised to increase the level recycling their vehicles through improved designs. While the cost of depollution of vehicles has to be covered by the manufacturers if it is more than the 'value' of the constituent parts, this does not mean the cost of achieving the recovery levels of $85 \%$ is met by each vehicle needs to be covered by manufacturers. It may make more sense to link the cost of reaching $85 \%$ of each vehicle model rather than brand, so that manufacturers would have to cover differential costs according the recoverability of individual model and hence be influenced to improve the 'design for recover', of less recoverable models. Of course this introduces extra information processing costs to the process, but may be recouped from lower cost model designs.

In order to gain maximum input from industrial partners, it may be prescient to introduce some kind of mix between regulation (where firms mainly aim at compliance only) and a voluntary or more fiscally aligned approach. Under the current regime there is limited incentive for industry to go beyond compliance and perhaps develop innovative solutions. If firms could directly link their environmental performance, e.g. recyclability, with operating profit for example, there would certainly be a greater chance of firms differentiating their responses. However, legislation often limits this differentiation, and so a voluntary code alongside fiscal incentives may in fact be more effective at mobilising companies' considerable resources to solve one of Europe's most pressing issues, the reduction of waste.

\subsection{Implications for other contexts}

Although an obvious point, the UK is not alone in reforming the way ELVs are dealt with, yet this has major implications for the contextual factors affecting this study. Compared to other countries, UK claims to have made a lower regulatory burden on firms. There is not empirical evidence to suggest that other countries have implemented the ELV directive in a less or more rigorous fashion, but ths would certainly be an important perspective to take. This has implications for both the effectiveness and efficiency of the whole ELV recovery process. Legislators may claim that their regulatory design has led to a more efficient process in terms of public 
and private resources (lower costs to enforce, lower costs to comply, for examples), but it has yet to be seen whether it would be as effective at meeting mandated targets. It should be pointed out that the effect of this is unlikely to affect vehicle manufacturer strategies, but could considerably affect cross-border trade in ELVs and hence the structure of Europe's dismantling and recycling industry.

\section{$5.4 \quad$ Further research}

Since any longitudinal study is limited firstly by the timeframe, it would be prescient to monitor developments in the UK visa vis the continued development of end of life vehicle strategies and the impacts on both compliance and competitive position of firms within the network. As already mentioned, it could be fruitful to examine the implementation of the ELV Directive across a number of member states, with different routes to compliance. Such as study could include Holland, Germany and Italy which have also had distinctive approaches to ELV recovery in the past, rules on scrappage for example, and duties included on the price of new vehicles.

\section{Bibliography}

Bitner M.J., Booms, B.H. and Tetreault, M.S. (1989), “Critical incidents in service encounters” in Bitner M.J. and Crosby, L.A. (Eds) Designing a Winning Service Strategy, American Marketing association, Chicago, IL, 89-991990

CEC [2000], End-of-life vehicle (ELV) Directive, (Brussels: European Commission).

Das, T.K and Teng, B-S [2000], 'A Resource-Based Theory of Strategic Alliances', Journal of Management, Vol. 26, No. 1, pp. 31-61.

den Hond, F [1998], Inertia and the strategic use of politics and power: a case study in the automotive industry, International Journal of Technology Management, Vol. 16, No. 7, pp. 641-54.

den Hond, F [1998], The similarity and hetergeneity theses in studying innovation: Evidence from the end of life vehicle case, Technology Analysis and Strategic Management, Vol. 10, No. 4, pp. 529-43.

den Hond, F and Groenewegen, P [1993], Solving the shredder waste problem: Cooperation among firms in the automotive industry, in K Fischer and J. Schot (eds.), Environmental strategies for industry: international perspectives on research needs and policy implications (Washington: Island Press), 343-62.

Denzin, N. and Lincoln, Y. (2005), Handbook of Qualitative Research. Sage, California.

Dyer, J.H and Singh, H [1998], 'The relational view: cooperative strategy and sources of interorganizational competitive advantage', Academy of Management Review, Vol. 24, No. 4, pp. 660-79.

Daugherty, P.J, et al. [2003], Reverse logistics in the automotive aftermarket industry, International Journal of Logistics Management, Vol. 14, No. 1, pp. 49-63.

Den Hond, F [1996], In search of a useful theory of environmental strategy: A case study of the recycling of end-of-life vehicles from a capabilities perspective, $\mathrm{PhD}$ (Vrije Universiteit).

Den Hond, F [1998], Inertia and the strategic use of politics and power: a case study in the automotive industry, International Journal of Technology Management, Vol. 16, No. 7, pp. 641-54.

Edvardsson , B. (1992), "Service breakdowns, a study of critical incidents in an airline", International Journal of Service Industry Management, Vol. 3, No. 4, pp. 17-29.

Eisenhardt, K. (1989), "Building theories from case study research”, Academy of Management Review, Vol. 14, No. 4, pp. $532-550$.

Flanagan, J.C. (1954), 'The critical incident technique', Psychological Bulletin, Vol. 51, No. 4, pp. 327-358.

Groenewegen, P and den Hond, F [1993], Product waste in the automotive industry, Business Strategy and the Environment, Vol. 2, No. 1, pp. 1-12.

Hakansson, H and Snehota, I [1995], Developing relationships in business networks (London: Routledge).

Harland, C [1996], 'Supply chain management: relationships, chains and networks', British Journal of Management, Vol. 7, No. Special Issue, pp. S63-S80.

Johnson, M.R and Wang, M.H [2002], Evaluation policies and automotive recovery options according to the European Union Directive on end-of-life vehicles (ELV), Journal of Automobile Engineering, Vol. 216, No. D, pp. 723-39.

Kumaran, D Senthil, et al. [2001], 'Environmental life cycle cost analysis of products', Environmental Management and Health, Vol. 12, No. 3, pp. 260-76. 
Kurylko, D [1997], 'Europe to regulate recycling', Automotive News Europe, Vol. 13, No. October.

Lamming, R.C., Johnsen, T, Zheng, J, and Harland, C [2000], 'An initial classification of supply networks', International Journal of Operations \& Production Management, Vol. 20, No. 5/6, pp. 675-92.

Lavie, D [2006a], 'Capability reconfiguration: An analysis of incumbent responses to technological change', Academy of Management Review, Vol. 31, No. 1, pp. 153-74.

Lavie, D [2006b], 'The Competitive Advantage of Interconnected Firms: An Extension of the Resource-based View', Academy of Management Review, Vol. 31, No. 3, pp. 638-58.

McEvily, B and Marcus, A [2005], 'Embedded Ties and the Acquisition of Competitive Capabilities', Strategic Management Journal, Vol. 26, No. 11, pp. 1033-55.

Orsato, R.J, den Hond, F, and Clegg, S.R [2002], 'The political ecology of automobile recycling in Europe', Organization Studies, Vol. 23, No. 4, pp. 639-65.

Roy, R and Whelan, R [1992], 'Successful recycling through value chain collaboration', Long Range Planning, Vol. 25, No. 4, pp. 62-71.

Shulman, N [1976], 'Network Analysis: A new addition to an old bag of tricks', Acta Sociologica, Vol. 19, No. 4, pp. 307.

Stuart, I. McCutcheon, R. Handfield, R. McLachlin, D. and Samson, D. 2002. "Effective case research in operations management: a process perspective.” Journal of Operations Management. Vol. 20, pp. 419-433.

Mazzanti, M. and Zoboli, R,(2005) Economic Instruments and Induced Innovation: The Case of End-of-Life Vehicles European Policies, (May). FEEM Working Paper No. 80.05. Available at SSRN: http://ssrn.com/abstract=740291.

Voss, C., Tsikritktsis, N. and Frohlich, M. (2002), “Case Research in Operations Management.” International Journal of Operations and Production Management. Vol 22, No, 2. pp. 195-219.

Winter, S. [2003], 'Understanding Dynamic Capabilities', Strategic Management Journal, Vol. 24, pp. 991-95.

Zaheer, A and Bell, G.G [2005], 'Benefiting from Network Position: Firm Capabilities, Structural Holes, and Performance', Strategic Management Journal, Vol. 26, pp. 809-25. 